
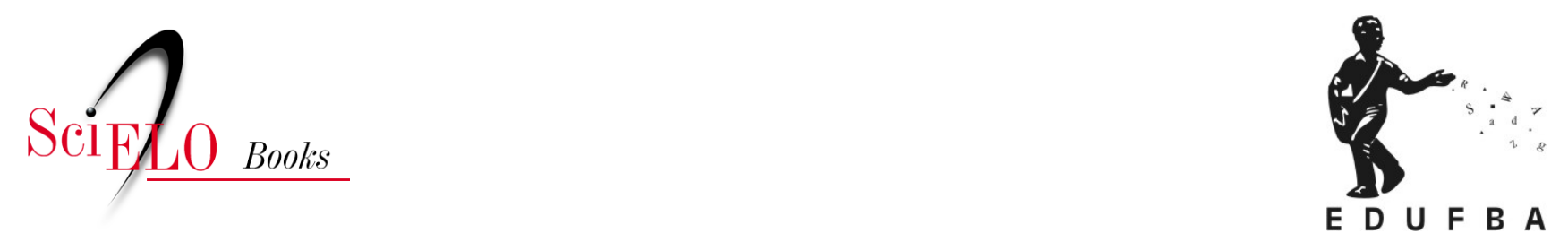

\title{
Policy \\ Emergência da odontologia social na Bahia
}

\author{
Sônia Chaves \\ Mona Lisa Souza
}

\section{SciELO Books / SciELO Livros / SciELO Libros}

CHAVES, S., and SOUZA, M.L. Emergência da odontologia social na Bahia. In: CHAVES, S.C.L. Política de saúde bucal no Brasil: teoria e prática [online]. Salvador: EDUFBA, 2016, pp. 319-336. ISBN 97885-232-2029-7. https://doi.org/10.7476/9788523220297.0013.

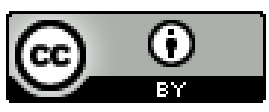

All the contents of this work, except where otherwise noted, is licensed under a Creative Commons Attribution 4.0 International license.

Todo o conteúdo deste trabalho, exceto quando houver ressalva, é publicado sob a licença Creative Commons Atribição 4.0. 


\section{Emergência da odontologia social na Bahia}

Sônia Chaves

Mona Lisa Souza

\section{A odontologia sanitária e social no Brasil e na Bahia}

Este estudo analisou os saberes e práticas de agentes sociais envolvidos com a emergência do espaço da odontologia social na Bahia, entre os anos 1940 e 1960. Foi um estudo sócio-histórico com recorte historiográfico baseado na perspectiva de análise sociológica de políticas de saúde de Pinell (2011), onde são analisados dois agentes, seus capitais e trajetórias nesse espaço de luta em torno do direito à saúde bucal. Foi reconstruída a biografia dos agentes do polo dominante desse período na Bahia, sua origem social, trajetória no campo burocrático e no campo científico, bem como as condições de possibilidade para emergência do espaço da odontologia social no estado.

Nos antecedentes históricos, cabe lembrar que a Faculdade de Medicina da Bahia foi a primeira da América Portuguesa, sendo instituída em 1808 com a chegada da corte portuguesa no Brasil. Nesse período, foi instituído o curso de cirurgia, porém a "arte de rancar dentes" continuou a ser realizada de maneira informal, com limitadas regulamentações, práticas que se perpetuaram até a segunda metade do século XIX. Somente em 1811, foi expedida a primeira carta de dentistas. Posteriormente, em 1820, veio para o Brasil diversos dentistas franceses o que muito influenciaram no ensino odontológico baiano. Outro fator importante para a saúde de maneira geral foi a criação da Junta de Higiene 
Pública, formada em 1850, objetivando o controle das epidemias, a exemplo da peste bubônica, febre amarela, dentre outros. (MACHADO et al., 1978)

Em 25 de outubro de 1884, data em que se comemora o dia do cirurgiãodentista no Brasil, pelo Decreto Imperial de n. ${ }^{\circ}$ 9311, conhecido como Reforma Saboia, é que a odontologia foi institucionalizada, passando a ter um curso regulamentado voltado para profissionalização da odontologia.

Os primeiros cursos de odontologia do Brasil foram criados a partir de 1884 nas Faculdades de Medicina do Rio de Janeiro e da Bahia. O provável motivo de esse curso ter sido criado na Bahia é exatamente porque aqui foi a primeira Faculdade de Medicina do Brasil, fundada nesse estado em 1808, conforme já ressaltado anteriormente, ainda que já houvesse um declínio de sua importância política desde a transferência da sede do governo imperial de Salvador para o Rio de Janeiro, ocorrida em 1762. Essa breve descrição histórica é reveladora do processo de esvaziamento da Bahia enquanto polo dominante no Brasil, com perda de poder, recursos e prestígio. Cabe destacar que essa nova conformação influenciou a consolidação das políticas de Estado, inclusive as de saúde, com a república instaurada em 1889, estendendo-se por todo o século XX. (JACOBINA; GALDINO, 2012)

Cabe destacar também que a emergência da odontologia social ocorre, diferentemente da medicina social (MACHADO et al., 1978), apenas no século XX, a partir dos trabalhos de Mário Chaves, cuja publicação Manual de odontologia sanitária, em três volumes, sistematiza essa disciplina "como aquela disciplina da saúde pública responsável pelo diagnóstico e tratamento dos problemas de saúde oral da comunidade”. (CHAVES, 1960, p. 24) Mário Chaves, juntamente com Alfredo Reis Viegas, inaugurou no Brasil o curso que confere a especialidade ao "Dentista de Saúde Pública" e as recomendações do Manual de odontologia sanitária orientaram as práticas, organização e docência da odontologia pública, cuja matriz foi influenciada principalmente pela saúde pública norteamericana. ${ }^{1}$

A reprodução desse curso formou gerações de dentistas sanitaristas brasileiros e latino-americanos. Dentre os sanitaristas formados, encontram-se

\footnotetext{
Na década de 1950, quando chega ao Brasil as ideias e práticas da odontologia sanitária, cujo agente principal no país foi o professor Mario Chaves. Em 1951, incorporou-se ao Serviço Especial de Saúde Pública (SESP), a Secção de odontologia sanitária, onde foi coordenador durante dois anos. Com a introdução da odontologia sanitária no SESP, iniciam-se atividades complementares às atividades assistenciais da previdência social, enquanto práticas odontológicas voltadas para escolares, influenciada pelas ideias da odontologia sanitária. (NARVAl, 1994)
} 
agentes importantes para a compreensão do espaço em estudo, como é o caso na Bahia de professor Jairo Diniz. Ademais, a tradução do Manual de odontologia sanitária para o espanhol, por ex-alunos do primeiro curso de saúde pública desenvolvido no Brasil, na Universidade de São Paulo (USP), vai possibilitar a disseminação desse conhecimento pela América Latina, Caribe e pelo mundo², expandindo a odontologia sanitária. (SOARES, 2011)

A odontologia social pode ser compreendida como sinônimo de odontologia sanitária, pois mantém suas mesmas bases conceituais como a ideia de "trabalho organizado na comunidade e para a comunidade, no sentido de obter as melhores condições possíveis de saúde bucal”. (CHAVES, 1986, p. 16) Reitera a relação desta com as disciplinas de saúde pública, sendo responsável pelo “[...] diagnóstico e tratamento dos problemas de saúde bucal da comunidade, entendendo a saúde bucal como aquela que abrange dentes e outras estruturas da cavidade bucal sob a responsabilidade do dentista." (CHAVES, 1986, p. 16)

Não foram encontrados estudos que analisem o surgimento do discurso e das práticas da odontologia social na Bahia. Nesse sentido, este capítulo analisou a emergência do espaço da odontologia social na Bahia nos anos 1940-1960, identificou e caracterizou alguns dos principais agentes do polo dominante, bem como suas trajetórias e inserção em distintos campos sociais, caracterizando também as condições históricas de possibilidade dessa emergência.

Para isso, foram revisados documentos históricos, incluindo o acervo da Faculdade de Medicina da Universidade Federal da Bahia (UFBA), no Terreiro de Jesus; foram localizadas as teses publicadas no período, bem como as matérias de jornais no período; foram entrevistados familiares e pessoas contemporâneas ao período analisado dos agentes investigados; foram reconstruídas as biografias dos agentes, buscando realizar um diálogo com a historiografia com respeito à emergência de práticas de odontologia social na conjuntura Vargas, na qual os agentes se situavam.

Do ponto de vista do referencial teórico, o conceito de espaço social se refere a um espaço de relações de força entre agentes engajados em lutas concorrentes em torno de um objetivo comum. Nesse caso específico, o "espaço da odontologia social" foi considerado um espaço onde há um conjunto de agentes que possuem diversas espécies de capital (econômico, cultural e social), como acúmulos, que são as principais formas de poder, onde as tomadas de posição são resultado da incorporação ou inculcação de princípios de visão 
de mundo, como disposições socialmente incorporadas ou habitus, resultado da conjunção da origem familiar, capital cultural e trajetória ao interior dos distintos campos sociais. (BOURDIEU, 1996) Não se buscou reconstruir toda a estrutura desse espaço social específico e datado, mas apenas revelar alguns dos fatos relacionados à trajetória dos agentes e das estruturas sociais naquele momento histórico.

\section{Condições de possibilidade na Era Vargas 1930-1954}

A análise das condições históricas de possibilidade do período de origem da odontologia social da Bahia é necessária para compreender as tomadas de posição e a disposições políticas dos principais agentes defensores da odontologia social.

É importante ressaltar que essa ampla conjuntura política (1930-1954) da chamada Era Vargas foi iniciada com a revolução de 1930, que representou o marco do início da Nova República do Brasil. Dessa maneira, chega ao fim a República Velha, representada pelas oligarquias dos estados de Minas Gerais e São Paulo. Assim, esse período da Nova República significou mudanças na forma de se pensar a saúde, economia e a política brasileira. Observa-se o nascimento de uma classe média que pressionava por mudanças no modo de se conduzir o país, que até então era dominado por uma pequena oligarquia ruralista e regionalista. Assim, a chegada de Getúlio Vargas ao poder marca um período de grande entusiasmo e construção da identidade nacional, com maior impulso à indústria nascente e criação também de diversas empresas estatais, a exemplo da Vale do Rio Doce e a Petrobras, em 1939.

Já os anos 1950 são considerados "os anos dourados", pois representaram o pós-guerra, com o fim do apogeu dos governos ditatoriais, do nazi-fascismo e o fim da ditadura Vargas. De outra forma, na Bahia, descobre-se o petróleo no bairro do Lobato. Porém, inicia-se a Guerra Fria com o mundo dividido em dois blocos: do capitalismo, liderado pelos Estados Unidos, e do socialismo, liderado pela União Soviética. Cria-se a Organização das Nações Unidades, polo de disputas do poder transnacional e o Estado de Israel. O Brasil, por outro lado, volta à democracia com as eleições presidenciais, pelas quais Gaspar Dutra é eleito presidente em 1946. O governo de Eurico Gaspar Dutra foi marcado pela promulgação da nova Constituição Brasileira de 1946, que, entre suas pautas importantes, estão: igualdade de todos perante a lei, liberdade de manifestação de pensamento, sem censura e separação dos três poderes. Em 1951, Getúlio 
Vargas volta ao poder, pois é eleito presidente pelo voto popular, sendo que seu governo continua marcado pela propaganda nacionalista e na promoção da industrialização. Em seu último mandato, Vargas cria as empresas estatais Petrobras, Eletrobrás e o Banco Nacional de Desenvolvimento, bem como os centros de profissionalização SENAI e SENAC e a siderúrgica de Volta Redonda.

No Brasil, no que tange à saúde pública, observa-se uma redução lenta da mortalidade por envelhecimento da população, há predomínio das doenças da pobreza e aparecimento da morbidade moderna (doenças do coração, neoplasias, acidentes e violências), com a industrialização, urbanização e mudanças nas condições de vida e saúde. A partir de 1930, inicia-se no país uma maior intervenção do Estado na saúde, além das ações de combate a epidemias com uma ação estatal de forma trifurcada (saúde pública, medicina previdenciária e saúde do trabalhador) através da institucionalização da saúde pública - Ministério da Educação e Saúde, e criação do Serviço Especial de Saúde Pública (SESP) - (CAMPOS, 2000) e da medicina previdenciária e saúde ocupacional - Ministério do Trabalho.

Apesar do período de grande avanço nas manifestações culturais e da perspectiva de progresso da nação nos anos 1950, uma grave crise econômica e política leva ao fim o governo Vargas, com seu suicídio em 1954, pondo fim ao Estado Novo. Em 1956, Juscelino Kubitschek ganha as eleições presidenciais e adota uma política desenvolvimentista com o famoso lema "cinquenta anos em cinco". Com a criação da cidade de Brasília, a capital do Brasil é transferida do Rio de janeiro. Na Bahia, em 1946, sobre o governo de Guilherme Carneiro da Rocha Marback, são criados, em 2 de julho desse ano, a UFBA e o Hospital das Clínicas da UFBA, tendo com reitor o médico Edgar Santos. Nessa conjuntura, cabe analisar a trajetória social dos dois agentes identificados (Aloysio Lopes-Pontes e Jairo Diniz).

\section{Aloysio Lopes Pontes: o pensamento higienista na odontologia social}

Aloysio Geraldo Souza Brito Lopes Pontes nasceu em 1918 na cidade de Salvador, Bahia, e faleceu em 1999, aos 81 anos. De família tradicional, com grande capital cultural e social, era irmão mais novo de irmã Dulce. Aloysio Lopes Pontes formou-se cirurgião-dentista pela Faculdade de Medicina da Bahia em 1941, sete anos depois de seu irmão mais velho, Augusto Raimundo Lopes Pontes. Seu pai, Augusto Lopes Pontes, também era cirurgião-dentista. Por essa formação, a família Lopes Pontes vivenciou as permanências e rupturas das 
práticas odontológicas realizadas na Bahia entre os períodos de 1920 a 1970, assim como os avanços científicos do conhecimento voltados para a melhoria da saúde bucal para a população brasileira e baiana.

Seu avô paterno, Manoel Lopes Pontes (1845-1899), era natural da cidade de Santo Amaro, foi deputado estadual, professor e fundador do colégio Santo Antônio. Seu avô materno, Manoel Joaquim de Souza Brito, foi médico, jornalista, escritor e professor. Sua mãe era professora, mas faleceu aos 26 anos de idade por complicações no parto do sexto filho. O pai de Aloysio, professor catedrático da Faculdade de Medicina da Universidade da Bahia, apoiava instituições filantrópicas pelo espírito de caridade com relações próximas a intelectuais baianos, a exemplo de Ruy Barbosa. Foi o fundador do Abrigo Filhos do Povo, que funcionava no bairro da Liberdade, ali criando o posto odontológico onde atendia a população pobre, gratuitamente. Era um católico filantrópico e social, que criou também os estatutos da Associação Obras Sociais Irmã Dulce (Figura 1).

Figura 1 - Aloysio Lopes Pontes (de óculos) ao lado de Irmã Dulce, sua irmã, e seu pai, Augusto Lopes Pontes e outros parentes

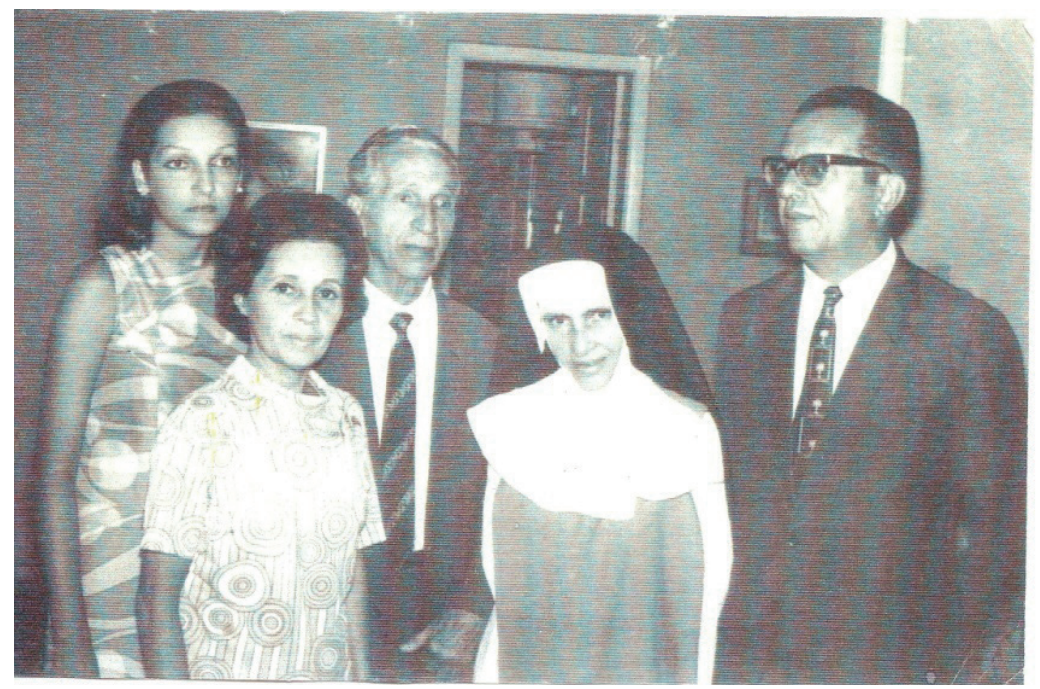

Fonte: acervo da família.

A trajetória no campo burocrático de Aloysio se inicia em paralelismo com sua carreira no incipiente campo científico odontológico baiano, sendo seu lócus principal a saúde do escolar ou assistência dentária escolar. Assumiu o 
cargo de cirurgião-dentista (classe G interino), em 1944, na Secretaria de Saúde Pública e Assistência Social da Bahia e, posteriormente, em 1950, prestou concurso para provimento do cargo efetivo de cirurgião-dentista, consolidando-se na classe J (1951), sendo logo promovido a chefe da Secção de Higiene da divisão médico-escolar do Departamento Estadual da Criança. Foi também dentista escolar do Colégio Central da Bahia e da Escola Maria Quitéria e, posteriormente, no consultório odontológico do $2^{\circ}$ Centro de Saúde Mário Andrea.

Tornou-se superintendente do Serviço Central de Higiene e Assistência Odontológica de Saúde Pública e Assistência Social, nomeado em 1967. É importante salientar que, desde 1935, na Bahia, a Secretaria de Saúde era conjunta com a de Educação, sendo intitulada Secretaria de Educação, Saúde e Assistência social. A separação dos órgãos ocorreu no governo do médico Luis Régis Pereira Pacheco (1951-1955).

Há relatos de dentista escolar na Bahia desde os anos 1920. Um processo movido por um dentista escolar para ganhos financeiros afirma

[...] Eu, cirurgião dentista Eneas Rocha, funcionário do ensino pertencente ao corpo administrativo da Escola Normal da Capital como encarregado do serviço dentário anexo à esta Escola [...] peço-vos o favor das competentes providencias concernentes à regularização na tabela anexa ao projeto de código da educação[...] "lei 1668 de 30 de agosto de 1923: fica criada a clínica dentária escolar anexa à Escola Normal da Capital. É também criada o lugar de zeladora do respectivo gabinete dentário". Essa lei também criou a clínica cirúrgica dentária na assistência pública [...] a lei 1846 de 14 de agosto de 1925 no art. 144: para educar praticamente os discentes do curso de professorado e os das escolas de aplicação, nos cuidados salutares de higiene profilática e de conservação dos dentes, haverá na escola normal da capital, um serviço de clínica odontológica provido do material indispensável e o cargo de cirurgiã-dentista nomeado por decreto do governador [...] o gabinete dentário anexo ao estabelecimento funcionará com o objetivo de educar praticamente os discentes nos cuidados salutares da higiene dos dentes. (BAHIA, 1937, p. 148)

No período em que Aloysio assumiu o cargo de cirurgião-dentista, o governador da Bahia, ainda na ditadura Vargas, foi o General Onofre Pinto Aleixo (1942-1945), que teve como secretário de Educação e Saúde o médico Aristides Novis. Dessa forma, é importante destacar que muitos profissionais da área de 
saúde estavam intimamente ligados a cargos políticos, constituindo uma rede de autoridades públicas envolvidas nas questões de higiene e saúde.

A trajetória na burocracia estatal se articula com sua carreira acadêmica na Faculdade de Odontologia da Bahia, onde foi docente-livre de Higiene e Odontologia Legal, com sua primeira tese defendida na Faculdade de Odontologia da Universidade da Bahia, intitulada Educação sanitária odontológica: aspectos e problemas, em 1954. Assim, acreditava que para o combate à cárie era necessária a educação sanitária do povo "prevenir para não curar eis o lema da odontologia preventiva", com grande influência da higiene que já havia sido disseminada no século XIX na Europa e mais tarde nos Estados-Unidos e que estava ganhando adeptos no Brasil. As práticas da odontologia social eram baseadas em campanhas e concursos do "mais belo sorriso" em escolas da rede pública (Figura 2).

Figura 2 - Grupo de dentistas na Escola Estadual Góes Calmon, nos anos 1953, em atividade da I Semana de Higiene Dentária do estado da Bahia com Aloysio segundo à direita. Presença do pai de Aloysio (primeiro à esquerda) como diretor da Faculdade de Odontologia

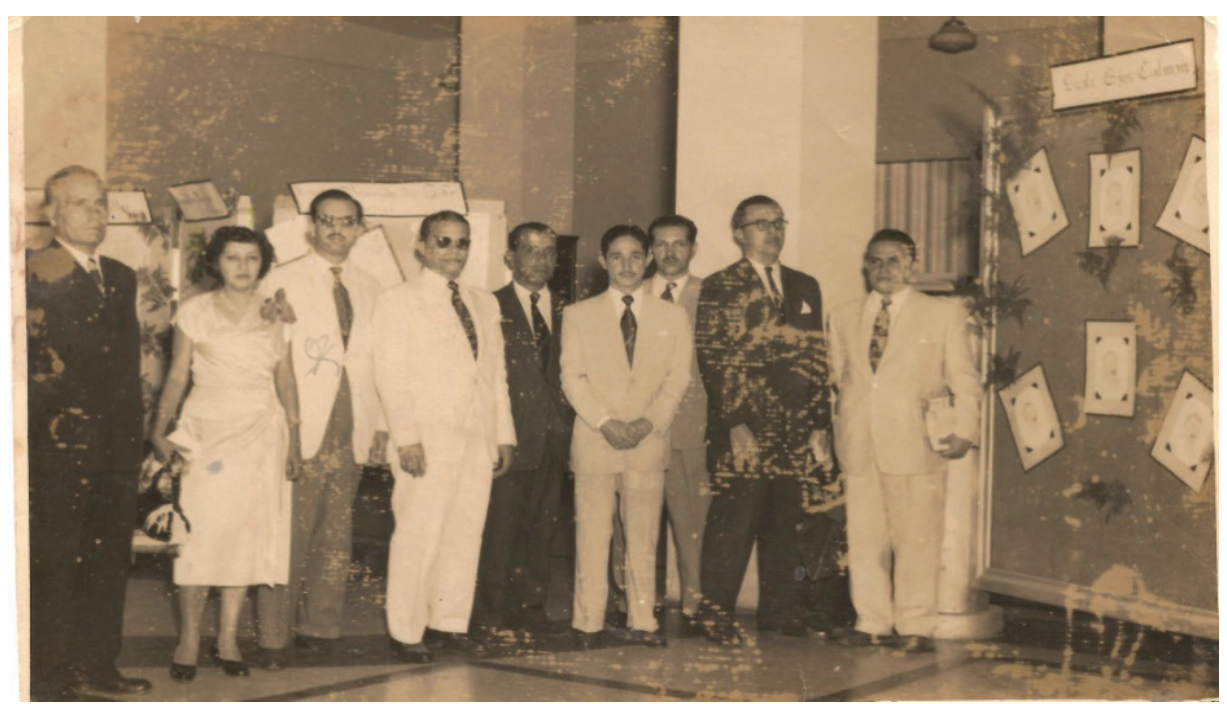

Fonte: acervo da família.

Nessa primeira tese, ele constrói um discurso em torno da cárie dentária que é importante destacar:

[...] desde os tempos mais recuados da vida no planeta que o homem sofre de cárie dentária, mas em tempo algum ela atingiu tão alto grau de incidência 
como atualmente, a ponto de ser chamada 'doença da civilização' e de ser incluída entre os flagelos da humanidade, [...] ela (a cárie dentária) constitui uma verdadeira praga [...] um dos mais sérios e devastadoras enfermidades da nossa época. (LOPES-PONTES, 1952 p. 3, 5, 6)

Há uma crítica à odontologia restauradora:

[...] o pior é que a função restauradora da odontologia não constitui, de todo, uma arma eficiente no combate à cárie. Por mais que obturemos as cavidades dentárias, não conseguiremos extinguir a 'praga' porquanto novos e novas cáries surgirão, de futuro. (LOPES-PONTES, 1952, p. 6)

A defesa da infância está em muitos trechos do seu trabalho:

Olhai as crianças e podereis avaliar o caráter de um povo. Elas são os indicadores do bem estar do nosso lar. A criança de uma democracia pode muito bem ser descrita como o barômetro da economia nacional [...] quantas crianças no Brasil nem sequer usam escovas de dentes! Tudo deve ser feito no Brasil em prol da higidez bucal, principalmente da criança porque como disse John Milton, poeta inglês: 'a infância mostra o homem assim como a manhã mostra o dia'. (LOPES-PONTES, 1952, p. 7, 11)

E propõe algumas intervenções baseadas em campanhas sanitária, do tipo "educação sanitária odontológica":

[...] ○ que se torna preciso, imperiosos, nessa campanha de educação sanitária odontológica é esclarecer por todos os meios possíveis, a importância dos dentes para a saúde, especialmente da criança. [...] execução de um programa de educação sanitária odontológica visando os pais, gestantes e crianças em idade pré-escolar e escolar e organização pelo estado da Bahia, à semelhança do outros estados do nosso país, de um completo, moderno e eficiente serviço de assistência odontológica à infância, visando principalmente o aspecto profilático e preventivo. (LOPESPONTES, 1952, p. 93)

Sua segunda tese, intitulada Das condições do primeiro molar permanente em 11.343 escolares baianos, trabalho de concurso para Cátedra de Higiene e Odontologia Legal da Faculdade de Odontologia da Universidade da Bahia, Aloysio 
manteve o seu discurso em defesa da disseminação da higiene. Entretanto, nesse trabalho, vai além do enfoque normativo e relato da experiência no Departamento Estadual da Criança do Estado da Bahia e produz o primeiro estudo epidemiológico sobre as condições de cárie dentária dos escolares baianos onde, segundo ele, os números, a eloquência dos dados estatísticos, seriam mais fortes do que palavras e conceitos. (LOPES-PONTES, 1962) A trajetória no campo burocrático e científico de ambos os agentes está sumarizada no Quadro 1.

\section{Quadro 1 - Trajetória nos campos científico e burocrático de dois agentes do polo dominante na origem da odontologia sanitária/Social na Bahia nos anos 1940-50}

\begin{tabular}{|c|c|c|}
\hline Agente & $\begin{array}{c}\text { Trajetória no campo burocrático } \\
\text { (Estado) }\end{array}$ & Trajetória no campo científico \\
\hline $\begin{array}{l}\text { Aloysio Lopes } \\
\text { Pontes }\end{array}$ & $\begin{array}{l}\text { Foi nomeado cirurgião dentista interino } \\
\text { do Serviço Público do Estado da } \\
\text { Bahia, em } 27 \text { de julho de 1944, por } \\
\text { Decreto Lei 12.076. Posteriormente, } \\
\text { foi dentista escolar, no Colégio } \\
\text { Estadual Central da Bahia (1944- } \\
\text { 1947). Depois, prestou concurso } \\
\text { para o Departamento do Serviço } \\
\text { Publico da Bahia, para provimento } \\
\text { efetivo do cargo de Cirurgião Dentista } \\
\text { da Secretaria de saúde Publica e } \\
\text { assistência Social (1950), passando } \\
\text { a Cirurgião dentista efetivo (1951). } \\
\text { Assumiu a chefia da Secção de Higiene } \\
\text { Assistência dentaria da Divisão Medico- } \\
\text { Escolar do Departamento Estadual da } \\
\text { Criança (1951-1962). Foi nomeado } \\
\text { Superintendente do Serviço Central } \\
\text { de Higiene e Assistência Odontológica, } \\
\text { da Secretaria de Saúde Publica e } \\
\text { Assistência Social. }\end{array}$ & $\begin{array}{l}\text { Assistente Honorário da Cadeira de } \\
\text { prótese da Faculdade de Odontologia da } \\
\text { Universidade da Bahia (1947-1954). } \\
\text { 1954, apresenta sua primeira tese } \\
\text { "Educação Sanitária Odontológica: } \\
\text { Aspectos e Problemas” para o cargo de } \\
\text { Docente Livre de Higiene e Odontologia } \\
\text { Legal da Faculdade de Odontologia da } \\
\text { Universidade da Bahia.Professor regente de } \\
\text { Higiene e Odontologia Legal da Faculdade } \\
\text { de Odontologia da Universidade da Bahia. } \\
\text { Catedrático Interino de Higiene e } \\
\text { Odontologia Legal, da Faculdade de } \\
\text { Odontologia da Universidade Federal da } \\
\text { Bahia (1961). } \\
\text { Enquadrado como Assistente de Ensino } \\
\text { superior (1964) e depois enquadrado } \\
\text { como professor adjunto (1967). } \\
\text { Enquadrado como professor catedrático da } \\
\text { cadeira de Higiene e Odontologia Legal pela } \\
\text { Universidade da Bahia (1967). Foi também } \\
\text { professor de odontologia sanitária da Escola } \\
\text { Bedicina e Saúde Pública. }\end{array}$ \\
\hline
\end{tabular}




\section{Quadro 1 - Trajetória nos campos científico e burocrático de dois agentes do polo dominante na origem da odontologia sanitária/Social na Bahia nos anos 1940-50}

\begin{tabular}{|c|c|c|}
\hline Agente & $\begin{array}{c}\text { Trajetória no campo burocrático } \\
\text { (Estado) }\end{array}$ & Trajetória no campo científico \\
\hline Jairo Diniz & 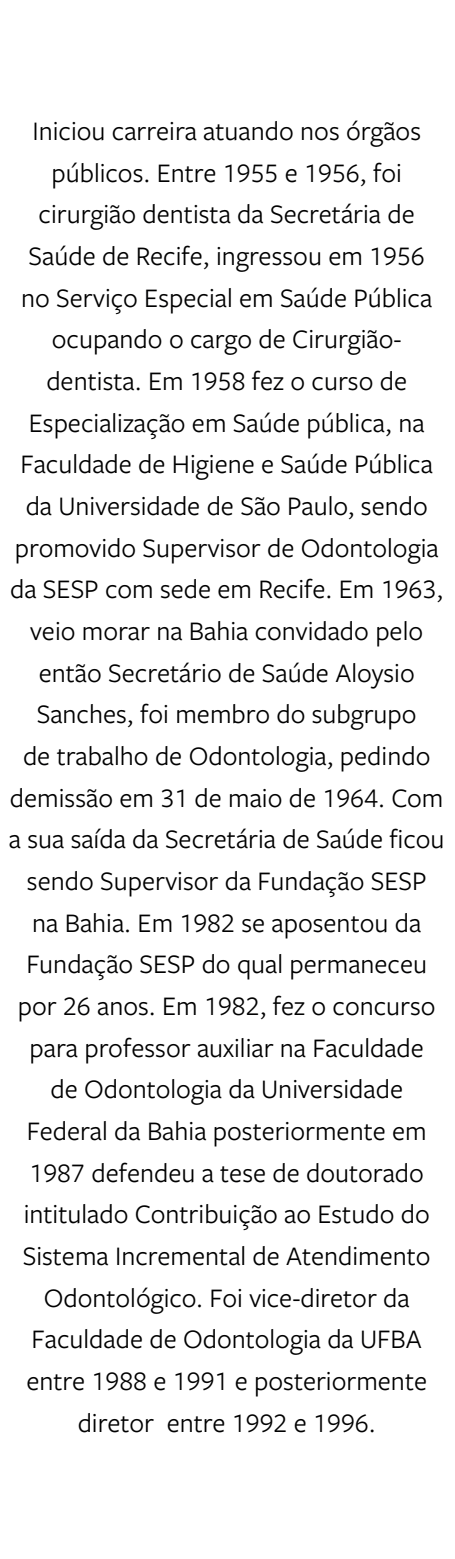 & 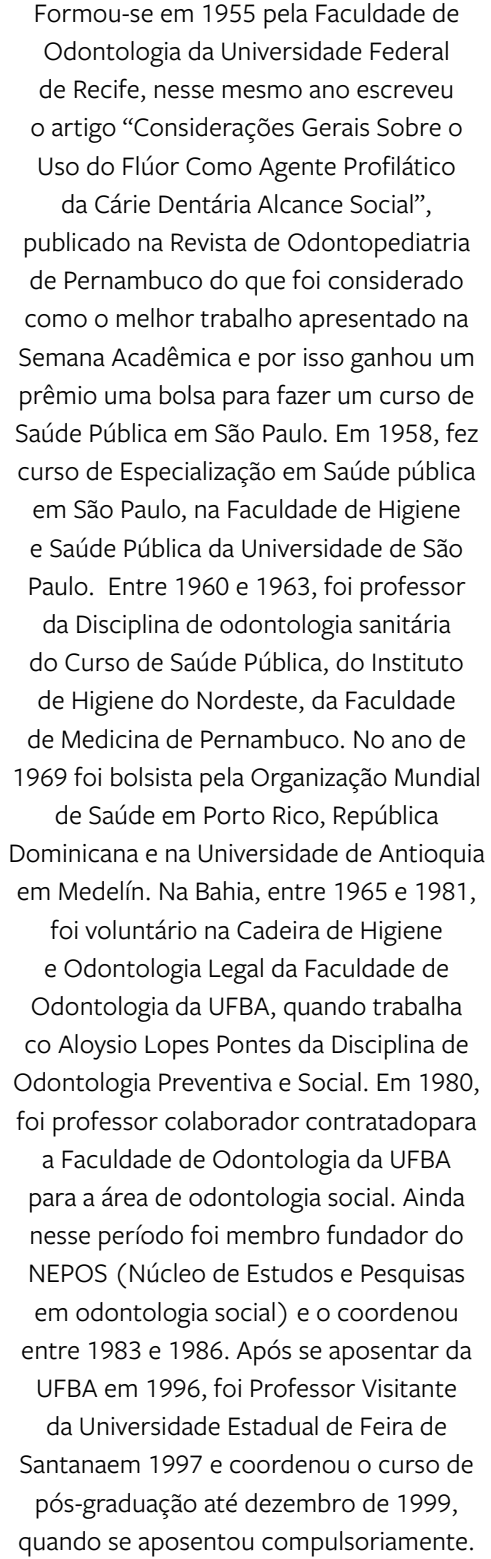 \\
\hline
\end{tabular}


Nesse sentido, percebe-se que Aloysio Lopes Pontes é de origem familiar com grande capital global acumulado com influência católica social, o que possivelmente o fez se envolver com as questões sociais e políticas de seu tempo. Interessou-se pela saúde pública quando assumiu o cargo de cirurgião-dentista da Secretaria de Saúde Pública e Assistência Social da Bahia, em 1944, e posteriormente foi promovido a chefe da secção de higiene da divisão médico-escolar do Departamento Estadual da Criança. Foi membro fundador da Associação Brasileira de Odontopediatria da Bahia.

Outra característica importante do seu capital social é sua influência na imprensa baiana. Exemplo disso são os artigos publicados em jornais, no qual todos estão relacionados ao tema odontológico e tendo como pedra angular a profilaxia. Foram cerca de 66 artigos publicados - sendo 20 em defesa da fluoretação das águas -, entre 1952 e 1970, nos principais jornais de circulação da Bahia, especialmente o jornal A tarde, um dos mais influentes em Salvador no período (Figura 3).

Dessa maneira, a grande maioria dos artigos publicados tiveram como tema central sempre a odontologia social, com objetivo de alertar o leitor para a importância de se cuidar dos dentes. Além disso, essas publicações tiveram também uma característica política, uma vez que vários artigos eram voltados para seu posicionamento a favor da fluoretação das águas, assunto de grandes discussões e posições opostas que se prolonga até a contemporaneidade.

Assim, além de trabalhos estritamente acadêmicos, Aloysio, fluente em francês e inglês, dialogava e se posicionava atento às transformações científicas odontológicas do período, com grande espaço na mídia impressa. As práticas comuns nesse período dos dentistas escolares eram as campanhas sanitárias em escolas na promoção de concursos em semanas de higiene dentária (Figura 4). 
Figura 3 - Matéria do jornal A Tarde, de Aloysio Lopes Pontes, em 23 de março de 1956, numa série de 20 publicações sobre os aspectos a favor e contra a fluoretação das águas

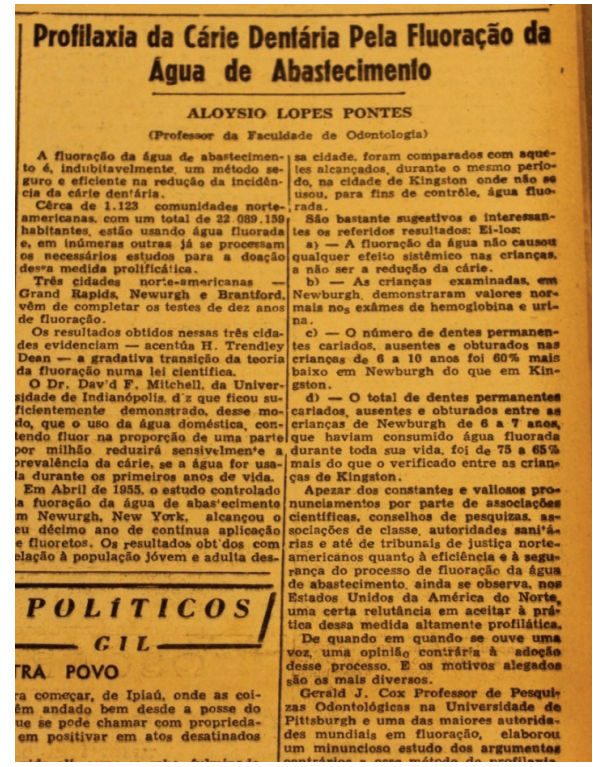

Fonte: acervo jornal A Tarde.

Figura 4 - Ações da Assistência Dentária Infantil de Pernambuco, em 1956, que presta assistência odontológica gratuita às crianças "pobres" do Recife

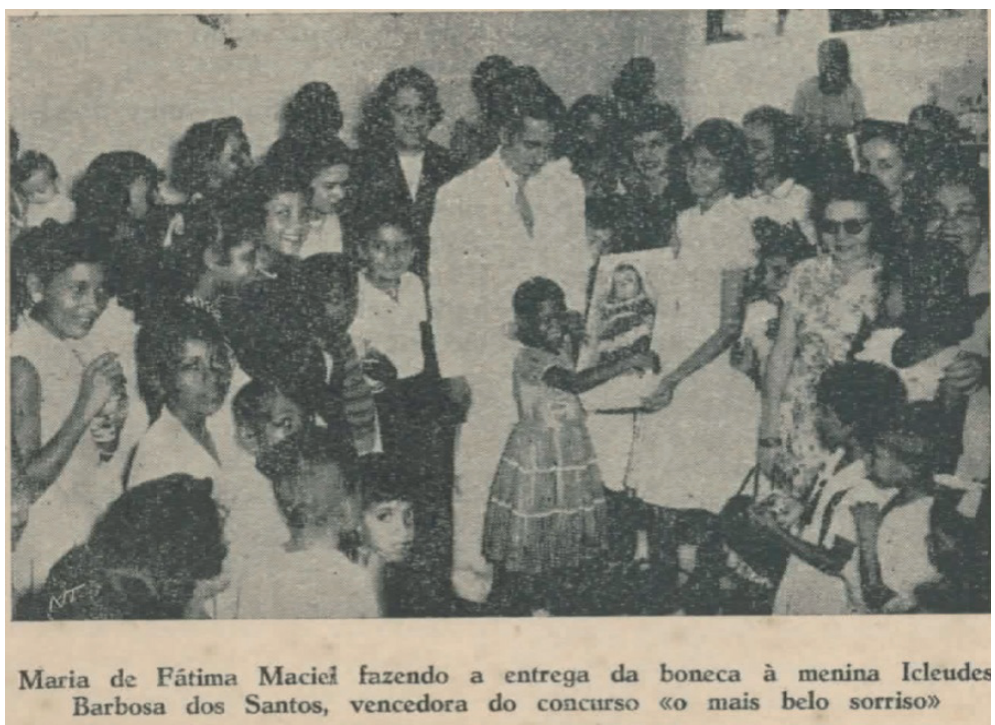

Fonte: Revista de Odontopediatria de Pernambuco (1956). 


\section{Jairo Diniz: a defesa da saúde como direito e o conhecimento sobre a ação do flúor}

Pernambucano, nasceu em Pedra, em 1929, e faleceu em Salvador, Bahia, em 2013, aos 84 anos. De família tradicional de interior, seu avô foi prefeito da sua cidade natal e seu pai e irmão foram coletores de impostos estaduais. Em 1955, forma-se cirurgião-dentista em Recife e, desde a graduação, é defensor da odontologia sanitária e social, tendo forte influência de Mário Chaves. Dessa forma, fez parte da equipe que implantou a odontologia sanitária no SESP, cujo pioneiro foi o professor Mario Chaves, que, em 1952, inaugurou o Sistema Incremental no Brasil na cidade de Aimorés, Minas Gerais, e implementou o primeiro sistema de fluoretação de águas de abastecimento público em Baixo Gandu, Espírito Santo, em 1953. Jairo Diniz defendia a saúde como um direito de todo o homem e que a odontologia prestava nobre colaboração à humanidade no setor da higiene e saúde pública além de atrelá-la ao "progresso", Como se observa no seu primeiro trabalho:

[...] A impossibilidade de dissociação da nossa ciência-arte com o progresso ascensional do mundo moderno. Caminhamos paralelamente com o seguimento das demais ciências contribuindo em igualdade de condições para a evidenciação e o alcance dos valores eugênicos e sociais, morais e espirituais da humanidade. (DINIZ, 1956, p. 24)

Saúde é uma das necessidades fundamentais da existência, é um direito do homem, sem distinção de raça, religião, ideologia política ou situação econômico-social. Basta meditarmos nas estatísticas de que nos países onde o poder estatal mais e melhor olha para os problemas de saúde da população. (DINIZ, 1956, p. 24)

Essa publicação, ainda como aluno de odontologia, marcará profundamente sua trajetória profissional, já que esse trabalho garantiu-lhe uma bolsa para fazer um curso de saúde pública em São Paulo pelo SESP, onde inicia uma rede de relações, que incluiu professor Mário Chaves, que posteriormente participará de sua banca de professor. Assim, ingressou em 1956 como cirurgião-dentista no Serviço Especial de Saúde Pública, trabalhando na cidade de Propriá, interior de Sergipe. O serviço dentário escolar do SESP foi implementado inicialmente em Aimorés, em 1952, mas também teve postos na Bahia. (NARVAI, 2006) Em 1958, finalmente fez o curso de Especialização em Saúde Pública, na 
Faculdade de Higiene e Saúde Pública da USP, sendo promovido supervisor de odontologia do SESP, em Recife. Em 1963, veio morar na Bahia, convidado pelo então secretário de saúde Aloysio Sanches, sendo membro do subgrupo de trabalho para elaborar um inventário dos recursos de odontologia do estado da Bahia. Foi assistente do secretário de saúde, nomeado por decreto pelo governador do estado da Bahia, pedindo demissão, em 31 de maio de 1964, com o Golpe Militar. Com a sua saída da Secretária de Saúde, ficou sendo supervisor da Fundação Serviços de Saúde Pública (FSESP), na Bahia (Figura 5). Em 1969, ainda como chefe da seção de odontologia da FSESP, foi contemplado com bolsa de estudos de quatro meses da Organização Mundial da Saúde e viajou para Colômbia, México, Estados Unidos e Porto Rico, para conhecer os diversos serviços de assistência odontológica integrados à saúde pública lá implantados. Em 1982, aposentou-se da FSESP, na qual permaneceu por 26 anos. Em 1982, fez o concurso para professor auxiliar na Faculdade de Odontologia da UFBA e posteriormente, em 1987, defendeu a tese de doutorado intitulada Contribuição ao estudo do sistema incremental de atendimento odontológico. Foi vice-diretor da Faculdade de Odontologia da UFBA, entre 1988 e 1991, e posteriormente diretor, entre 1992 e 1996. Foi também professor na Universidade Estadual de Feira de Santana (UEFS) até sua aposentadoria compulsória.

Figura 5 - Atividades de Assistência Dentária ao Escolar dos Serviços Especiais de Saúde Pública nos anos 1950. Jairo Diniz realizando exame epidemiológico em escolares no interior da Bahia e supervisão de aplicação tópica de Flúor em Pernambuco, 1957.
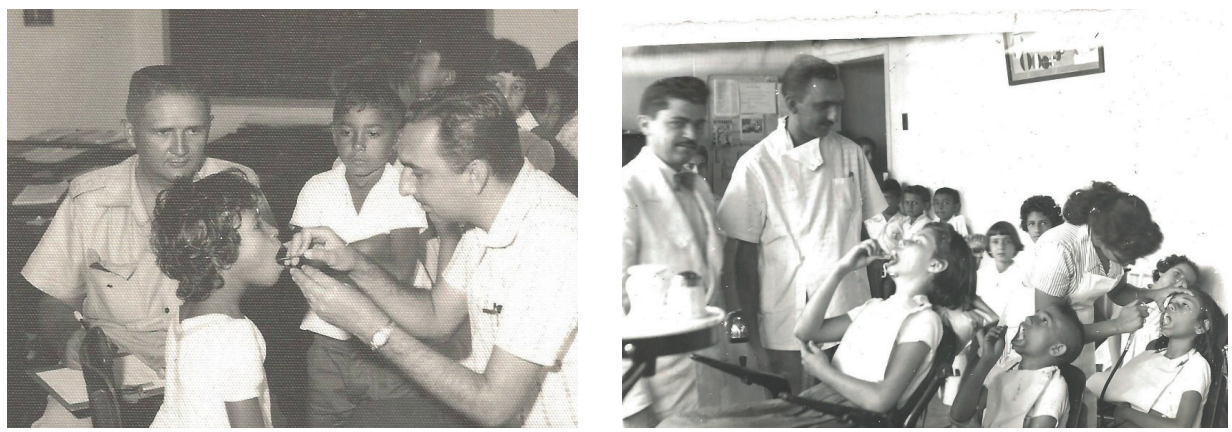

Fonte: Acervo familiar. 


\section{Considerações finais}

A emergência da odontologia social na Bahia esteve relacionada a condições de possibilidade concretas do avanço da intervenção estatal na saúde da Era Vargas, incluindo a oferta de serviços públicos odontológicos, ainda que limitados. Um exemplo disso foi a expansão do cargo de cirurgião-dentista escolar, ligado ao movimento de proteção da infância no Brasil, como o caso de São Paulo (MARTINO; BOTAZZO; ZILBOVICIUS, 2010) e da Bahia, com a puericultura e hospitais para crianças, já revelado em estudos anteriores (SOUZA; BARRETO, 2011) que o mesmo contexto foi observado na Europa e Estados Unidos, ao final do século XIX. (MARTINO; BOTAZZO; ZILBOVICIUS, 2010) A invenção do cargo de dentista escolar deve ser maior esclarecida em estudos posteriores, haja vista que sua inserção na Bahia data dos anos 1920, com trabalho em gabinete dentário na escola e com "o objetivo de educar os alunos nos cuidados salutares da higiene dos dentes". 3

Os principais agentes identificados na Bahia, nos anos 1950-1960, foram Aloysio Lopes Pontes, de família tradicional de alto capital cultural, e Jairo Diniz, com carreira consolidada no SESP. Ambos foram professores da Faculdade de Odontologia da UFBA, com trajetórias profissionais distintas, mas com disposições muito próximas. Aloysio Lopes Pontes teve inserção no campo burocrático como dentista da Secretaria de Assistência Social, em 1942, com posterior inserção no campo científico, nos anos 1950. Por outro lado, Jairo Diniz foi profissional de dedicação exclusiva do Serviço Especial de Saúde Pública, agência bilateral Brasil-Estados Unidos, fundada no período da Segunda Guerra Mundial, que só tardiamente na carreira, assume o cargo de professor.

As contribuições, nos anos 1940 e 1950, na Bahia, para a emergência desse espaço podem ser de dois tipos. A primeira foi a construção social do problema da cárie dentária como flagelo comparável às epidemias do período, ou como "flagelo moderno da humanidade", presente no pensamento higienista de Aloysio Lopes Pontes, através do qual a higiene é vista como a única intervenção possível pelos limites do conhecimento científico no campo médico desse período, no que se refere ao uso do flúor, cujo uso se consolida apenas no final dos anos 1950, com grande influência do SESP. A segunda contribuição foi 
a defesa do cirurgião-dentista escolar no estado da Bahia, com foco na proteção da infância.

Já em 1912, em São Paulo, iniciou-se a Assistência Dentária Escolar na atenção pública, de início, sob o viés da filantropia e, já em 1913, com auxílios públicos provindos da prefeitura da cidade. A presença do serviço dentário em São Paulo tem relação com a defesa da assistência à criança e, principalmente, da assistência ao escolar. Em 1925, o cargo de inspetor dentário na Inspetoria Médico Escolar é criada, também em São Paulo. A maior expansão nesse estado será nos anos 1950, quando já se observa mais de 1000 dentistas escolares em 732 clínicas odontológicas públicas. (DINIZ, 1955)

Nossa hipótese é que o pensamento social na odontologia inicia-se na recém-criada especialidade da odontopediatria, ainda em processo de consolidação no seu primeiro Congresso Nacional, em 1955, tendo como locus principal a escola, especialmente a partir dos avanços no conhecimento quanto ao uso do flúor tópico para prevenção da cárie dentária nos anos 1950. Jairo Diniz, ao utilizar os termos "odontopediatria estatal ou pública", aponta nessa direção. Essas evidências podem explicar em parte o predomínio atual do modelo centrado no escolar, comum ainda no século XXI, ainda a ser superado pelo movimento da saúde bucal coletiva. A luta em defesa de uma odontologia social iniciada por Aloysio Lopes Pontes e por Jairo Diniz, nos anos 1950, ainda é, portanto, um desafio na contemporaneidade.

\section{Referências}

BOURDIEU, P. Razões práticas: sobre a teoria da ação. 6. ed. Campinas, SP: Papirus; 1996. BOURDIEU, P. Sur l'État: Cours au Collège de France 1989-1992. Paris: Éditions Raisons D’agir ; Éditions Seuil, 2012.

CAMPOS, A. L. V. Políticas internacionais de saúde na era Vargas: o serviço especial de saúde pública. In: GOMES, A. C. (Org.) Capanema: o ministro e seu ministério. Rio de Janeiro: Fundação Getúlio Vargas, 2000.

CHAVES, M. M. Manual de odontologia sanitária. São Paulo: Ed. USP, 1960. Tomo I. CHAVES, M.M. Odontologia sanitária. Washington, DC: OPS, 1962. (Publicação Científica 63).

CHAVES, M. M. Odontologia social. 3. ed. Rio de Janeiro: Artes Médicas, 1986.

CHAVES, S. C. L.; CRUZ, D. N. Desafios contemporâneos à organização da atenção em saúde bucal na Bahia. Revista Baiana de Saúde Pública, Salvador, v. 36, n. 1, p. 621-639, jul./ set. 2012. 
CUNHA, E. S. História da odontologia no Brasil (1500-1900). 2. ed. Rio de Janeiro: Científica, 1952.

DINIZ, J. Contribuição ao estudo do sistema incremental de atendimento odontológico. 1987. 144 p. Tese (Doutorado em Odontologia) - Faculdade de Odontologia, Universidade Federal da Bahia, Salvador, 1987.

DINIZ, J. Considerações gerais sobre o uso do Flúor como agente profilático de cárie dentária: alcance social decorrente. Revista de Odontopediatria da Associação Pernambucana de Odontopediatria, Recife, Ano IV, n. 9 p. 23-34, jan./dez. 1956.

JACOBINA, T. A.; GALDINO, B. História e saúde na Bahia. 2012. Disponível em: <http:// www.isc.ufba.br/saudeehistoria/Artigo_Historia_e_Saude_na_Bahia>. Acesso: 20 jun. 2014.

MACHADO, R. et al. Danação da norma: a medicina social e constituição da psiquiatria no Brasil. Rio de Janeiro: Edições Graal, 1978.

MARTINO, L. V. S.; BOTAZZO, C.; ZILBOVICIUS, C. Os caminhos públicos da odontologia paulista no início do século XX. Cadernos de História das Ciências, São Paulo, v. 6, n. 1, p. 141-156, jan./jul. 2010.

MOLESINI, J. A. O. A Reforma Sanitária na Bahia: um lugar na história (1987 a 1989). 2011. 263 f. (Doutorado em Enfermagem) - Universidade Federal da Bahia, Salvador, 2011.

NARVAI, P. C. Odontologia e saúde bucal coletiva. Rio de Janeiro: Hucitec, 1994.

NARVAI, P. C. Saúde bucal coletiva: caminhos da odontologia sanitária à bucalidade. Revista de Saúde Pública, São Paulo , v. 40, n. esp., p. 141-147, 2006.

PINELL, P. Análise sociológica de políticas de saúde. Rio de Janeiro: Editora Fiocruz, 2011 PONTES, M. R. Irmã Dulce dos Pobres. 13. ed. Rio de Janeiro: Sindicato Nacional, 1991.

LOPES-PONTES, A. G. Das condições do primeiro molar em 11.343 escolares baianos. 1962. 123 f. Tese (Concurso à Cadeira de Higiene e Odontologia Legal) - Faculdade de Odontologia da Universidade Federal da Bahia, 1962.

LOPES-PONTES, A. G. Educação sanitária odontológica: aspectos e problemas. 1954. 107 f. Tese (Concurso à Cadeira de Higiene e Odontologia Legal) - Faculdade de Odontologia da Universidade Federal da Bahia, 1954.

\section{REVISTA DE ODONTOPEDIATRIA DA ASSOCIAÇÃO PERNAMBUCANA DE} ODONTOPEDIATRIA, Recife, Ano IV, n. 9 p. 23-34, jan./dez. 1956.

SOARES, C. L. M. A Constituição da saúde bucal coletiva no Brasil. 2014. 180 f. Tese (Doutorado em Saúde Pública) - Instituto de Saúde Coletiva, Universidade Federal da Bahia, Salvador, 2014.

SOUZA, C. M. C.; BARRETO, M. R. N. História da Saúde na Bahia: instituições e patrimônio arquitetônico (1808-1958). São Paulo: Manole, 2011. 